\title{
Research on the management system of lithium battary
}

\author{
Wenqiang $\mathrm{Xie}^{1, *}$ \\ ${ }^{1} \mathrm{Xi}$ 'an Research Institute of China Coal Technology \& Engineering Group Corp
}

\begin{abstract}
Lithium battery is the first choice for the energy source of explosion-proof electrical equipment because of its small size, light weight and large energy. In order to ensure the safety, improve the battery life and prolong the service life of the lithium battery, it is necessary to study the lithium battery management system. For this reason, the article uses the modular design idea to design a lithium battery intelligent management system. The system takes the microcontroller as the core to control the current voltage signal sampling, power indicator, serial communication and other management functions, and combined with the software process, the implementation of the system control algorithm is described in detail. Finally, combined with the system software and hardware function, and through repeated experiments and continuous improvement and improvement, it can be run safely and stably.
\end{abstract}

\section{Introduction}

The rapid growth of the application portable electronic equipment, the application of lithium battery has opened up a broad prospect, especially for the use of lithium batteries for instruments and meters in coal mines. It is well known that the power use of lithium battery requires the battery series and parallel connection to increase the voltage and capacity, due to the inconsistency of the battery in the battery pack, if one of the batteries has problems, the whole battery cannot continue to work for safety reasons. When the battery appears overcharge, excessive short circuit, temperature over limit and so on, the battery management system will judge according to the abnormal data collected, and then send out the state signal, and through the controller to the charge and discharge protection, temperature protection, equalization management circuit and other corresponding control signals, real-time monitoring its use status, timely protection. And the various operating data of the battery to store backup, establish the use of archives, in order to provide reference for the safe use and maintenance of batteries in the future. Therefore, according to the standards of GB3836-2010 and MT1051-2007 series standards, a lithium battery intelligent management system is designed to meet the safety performance management of lithium ion batteries in coal mine.

\section{System design and composition}

The management system of lithium battery mainly includes the intelligent charging, battery pack equalization and other protection circuit, the supporting management device realizes the hardware and software protection and intelligent energy management. The management device collects all kinds of battery data, and uses the software set rules to protect and optimize all the cell batteries in the battery pack. The battery management system design the main tasks, as shown in table 1:

Table 1. Main tasks of battery management system design.

\begin{tabular}{|c|c|c|}
\hline Task & Content & Execution unit \\
\hline $\begin{array}{c}\text { Prevent } \\
\text { overcharging }\end{array}$ & $\begin{array}{c}\text { Voltage limiting } \\
\text { current limit }\end{array}$ & $\begin{array}{c}\text { Charging control } \\
\text { circuit }\end{array}$ \\
\hline $\begin{array}{c}\text { Prevention of } \\
\text { over - discharge }\end{array}$ & $\begin{array}{c}\text { Voltage limiting } \\
\text { current limit }\end{array}$ & $\begin{array}{c}\text { Discharge } \\
\text { control circuit }\end{array}$ \\
\hline $\begin{array}{c}\text { Temperature } \\
\text { control }\end{array}$ & $\begin{array}{c}\text { Refrigerating } \\
\text { plant }\end{array}$ & $\begin{array}{c}\text { Heating and } \\
\text { cooling part }\end{array}$ \\
\hline $\begin{array}{c}\text { Status } \\
\text { information }\end{array}$ & $\begin{array}{c}\text { Voltage, current, } \\
\text { temperature }\end{array}$ & Digital display \\
\hline $\begin{array}{c}\text { Balanced } \\
\text { management }\end{array}$ & $\begin{array}{c}\text { Performance } \\
\text { matching }\end{array}$ & Equalizer circuit \\
\hline
\end{tabular}

In short, the battery management system is the core of the safe use of lithium battery, it can collect all kinds of data in real time, deal with the data, and issue control signal to protect and balance the whole battery pack, calculate the residual capacity of the battery, ensure the safety of lithium battery, improve the battery life and prolong the service life of lithium battery.

\section{System hardware design}

The system hardware design uses the microcontroller control scheme, real-time detection of battery current, voltage and temperature parameters, and then carries on the data processing, calculates the residual battery power of the battery pack by the appropriate algorithm, and sends the battery voltage, current, temperature and residual capacity into the display module, real-time display, in order to ensure the timely grasp of the battery

* Corresponding author: xwq7323182@163.com 
state parameters, ensure the use of safety. The hardware control scheme structure diagram, as shown in figure 1:

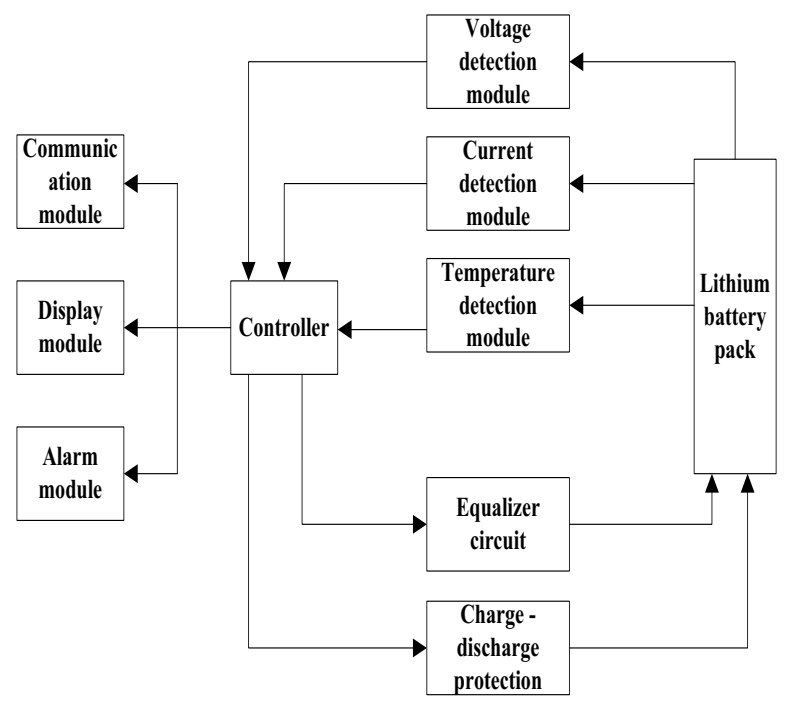

Fig. 1. Structural diagram of hardware control scheme

\subsection{Voltage measurement module}

The system takes the direct measurement method, and takes the voltage of the two ends of the monomer cell into the differential amplifier circuit for sampling. In order to eliminate the effect of load change on the output voltage, we connect a voltage follower at the output end, so that the input resistance tends to infinity, and the output resistance tends to zero. After the voltage follower output, and then use the analog switch to select the channel to sample, directly into the microcontroller of the 10 - bit ad converter. Since it is an integrated analog to digital converter in the chip, it is not necessary to add the sampling and holding circuit to measure the voltage of any cell.

\subsection{Current measurement module}

The current is a key parameter for estimating the capacity of the battery, and it is an important reference factor for the over-current protection circuit of the battery charging and discharging process. Therefore, the current sampling accuracy, anti-interference ability and linearity are very high in the lithium battery intelligent management system. The system uses the hall current sensor as the current detection device, and realizes the isolation with the main circuit.

\subsection{Temperature measurement module}

The battery will produce heat in the process of charge and discharge, the temperature of the battery has a very important relationship with the performance and working status of the battery. The temperature will greatly affect the efficiency of the battery charging, and even cause serious damage to the battery. The temperature difference between the batteries will increase the imbalance between the battery cells, which greatly affects the service life of the battery. Therefore, the temperature measurement is also very important in the system. The temperature measurement in the system is based on the temperature sensor produced by Dallas company.

\subsection{Charging and discharging protection module}

The normal voltage range of lithium battery is $4.2 \mathrm{v} \sim$ $2.7 \mathrm{v}, 4.2 \mathrm{v}$ is the protection value of charging voltage, and $2.7 \mathrm{v}$ is the voltage protection value of discharge. The Provision and Guo delay time are all $1 \mathrm{~s}$, and the Guo delay time is determined according to the current size, the more current the current is, the smaller the current delay time. When the voltage of all batteries is between $4.2 \mathrm{v}$ and $2.7 \mathrm{v}$, the battery is in the normal charge and discharge state; When the voltage of any section of the battery exceeds $4.2 \mathrm{v}$ and the duration is more than $1 \mathrm{~s}$, the control signal is given to turn off the MOSFET tube and the charging circuit is disconnected; When the voltage of the battery is less than $2.7 \mathrm{v}$ and the duration is more than $1 \mathrm{~s}$, the control signal is issued to shut off the MOSFET and disconnect the discharge circuit. When the current sampling circuit is converted to a voltage greater than the short-circuit protection reference voltage, the protection circuit will immediately shut off the control MOSFET and disconnect the discharge circuit to prevent the flow or short circuit.

\subsection{Equalizing circuit module}

The realization of equalization circuit is through the collection of lithium battery terminal voltage, internal resistance, current, temperature and other information, and then through the SOC estimation algorithm to calculate the state of charge of a monomer cell, in order to obtain a reasonable equilibrium strategy. Therefore, the preparation of these external parameters is crucial. After the data acquisition, the analysis of the specific control scheme, through the control circuit to control the operation status of each balanced module, and ultimately complete the balance of the whole system. The system is realized by active equalization method.

\subsection{Hardware anti - interference measures}

The battery management system contains a variety of electronic devices and different types of lines, relatively complex. The interference between the various transmission channels can affect the work of the controller, or even cause damage. The battery management system is in the electric vehicle, the working environment is complex, there is noise interference around. In order to ensure the system can operate stably in complex operating conditions, the following measures are introduced to the relative stability and accuracy of the collected data.

The wiring design of PCB is also very important. Pcb provides the electrical connection between the circuit 
components. the design of the circuit has great influence on the anti-jamming of the system. the unreasonable design of the circuit board will lead to the serious distortion of the data acquisition and even the system can not work. Therefore, the anti-interference measures are particularly important in the PCB design. When arranging components, try not to use jumpers, generally use a 45-degree corner to reduce the wire impedance and distributed capacitance inductance. At the same time, according to the function of the circuit layout, so as to prevent the different regions of RF current coupling caused interference. The different power supply must be separate wiring, such as the system has $+5 \mathrm{v},+12 \mathrm{v}$ and so on different voltage must pay attention to separate; On the ground wire, the digital ground and analog ground should be separated, and the width of the power line and ground wire should be larger than the general signal line, so as to improve the anti - interference.

\section{System software design}

The main task of the lithium battery management system is to measure the voltage, current and temperature of the battery, through the analysis of the measurement parameters, the battery charge and discharge protection system to achieve effective management. Parameter measurement is the basic part of the whole battery management system, the battery charge and discharge protection and SOC estimation are based on this part. When the measured value exceeds the upper limit set value, the battery charge and discharge protection circuit shall be protected by the system.

Because of the inconsistency of the single cell, such as operating temperature, humidity, chemical composition and other characteristics, when the battery is charged with the same power supply, the battery charge or discharge will be different, when the battery needs to be effectively balanced, otherwise it will greatly shorten the life of the battery. For the estimation of residual power, the corresponding relationship between open circuit voltage and battery power is estimated, and the current value of detection is integrated by ampere hour integral method in charge and discharge, which can be realized by timer interrupt of single chip microcomputer.

CAN communication is the intermediary between the battery management system and the central control system. the battery management system sends the information of the battery voltage, current, temperature and SOC to the central control system through the CAN bus, and displays the battery pack status. In the system, the central control system sends data signals to different modules, gets the data information needed by the system, and then summarizes the data and makes corresponding processing and display. The main program flow diagram of the system, as shown in figure 2:

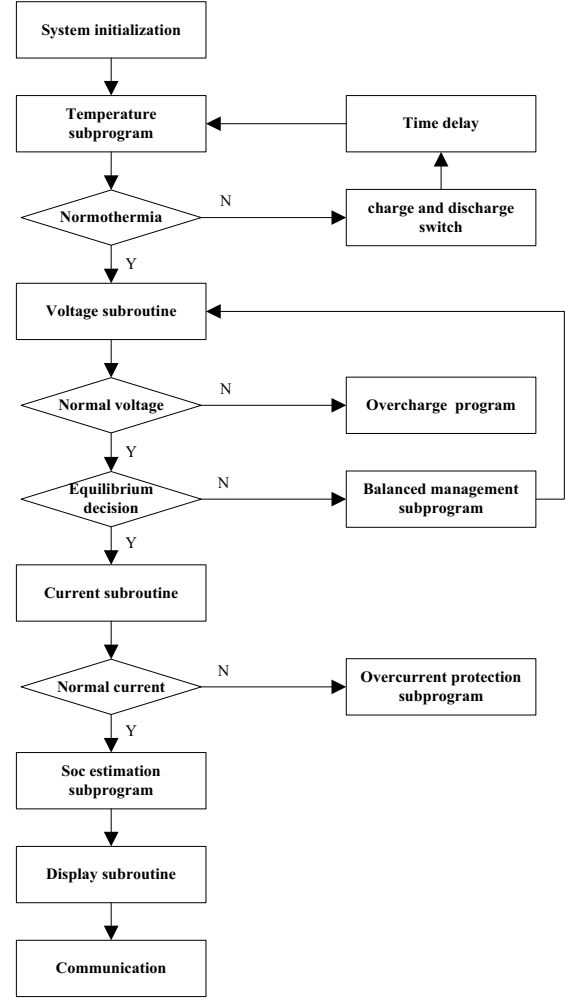

Fig. 2. System master program flow chart

\subsection{Flow chart of measurement of voltage and current}

Fig. 3 is a flow chart of the voltage measurement subroutine. The current measurement is basically consistent with the voltage measurement in the software implementation, the current measurement is only in the hardware circuit, the measured circuit is converted into voltage, and then sent to the microcontroller ad converter.

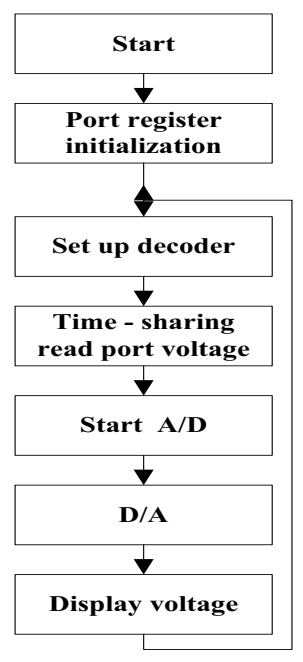

Fig. 3. Process flow chart of voltage measurement subprogram

\subsection{Balanced control subprogram chart}

The equalization strategy adopted by the system is to take the active and balanced way in the battery charging, 
which can improve the charging efficiency, save the power consumption, and can effectively balance the battery pack. The balanced control subroutine diagram is shown in figure 4:

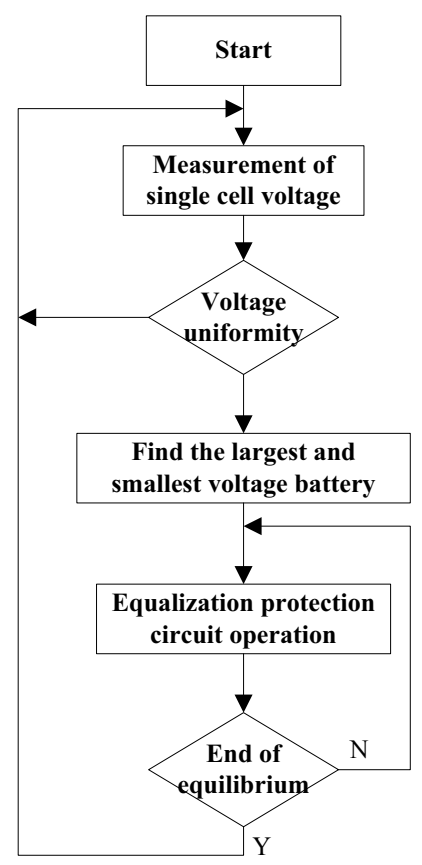

Fig. 4. Flow chart of balanced control subprogram

\section{System test}

Using the system to collect the voltage and temperature data of 24 series lithium battery, and the voltage balance of lithium battery. The monitoring data of 10 series lithium batteries are compared, and the results are shown in table 2. It can be seen that before the voltage equalization of the lithium battery, the maximum pressure difference between the 10 series lithium battery is $0.289 \mathrm{~V}$, the maximum pressure difference after adopting the system is only $0.052 \mathrm{~V}$.

Table 2. Pre-and post-equilibrium voltage comparison of lithium battery

\begin{tabular}{|c|c|c|c|c|c|}
\hline Number & 1 & 2 & 3 & 4 & 5 \\
\hline $\begin{array}{c}\text { Equalizing front } \\
\text { voltage (V) }\end{array}$ & 3.412 & 3.386 & 3.316 & 3.285 & 3.136 \\
\hline $\begin{array}{c}\text { Equalizing post } \\
\text { voltage (V) }\end{array}$ & 3.356 & 3.347 & 3.366 & 3.352 & 3.319 \\
\hline Number & 6 & 7 & 8 & 9 & 10 \\
\hline $\begin{array}{c}\text { Equalizing front } \\
\text { voltage (V) }\end{array}$ & 3.359 & 3.219 & 3.227 & 3.401 & 3.123 \\
\hline $\begin{array}{c}\text { Equalizing post } \\
\text { voltage (V) }\end{array}$ & 3.322 & 3.314 & 3.321 & 3.326 & 3.329 \\
\hline
\end{tabular}

\section{Conclusion}

In order to meet the safety performance management of lithium ion battery used in coal mine, a lithium battery intelligent management system is designed according to GB3836-2010 and MT1051-2007 series standards. From the system principle method, hardware functional circuit, software design and implementation of three aspects comprehensive analysis, lithium battery charging, discharge characteristics, voltage acquisition, current collection, protection circuit design and the balance management of the battery were studied and tested, and the test results were given. Through the actual test, the system can improve the consistency of lithium battery, effectively achieve the battery equalization, which is conducive to prolong the battery life and battery life, greatly reducing the workload of on-site maintenance.

\section{References}

1. Cui Yufeng, Yang Qing, Zhang Linshan, Research on the development status and charging technology of electric vehicles at home and abroad[J]. Yunnan power technology. 2010.

2. Xie Bin, Research on SOC identification and equilibrium management of electric vehicle lithium battery group [D], Guangzhou: south China university of technology. 2013.

3. Yueren Chao. Research on battery management system [D]. Beijing: Beijing jiaotong university. 2010.

4. Liu wenhao, Chen Jingyuan, Shen Wei, Design of $\mathrm{Li}$ - ion power battery protection circuit based on pic16 [J]. Journal of Zhejiang university of technology, 2008.

5. Wang Wei, Luo Guangyi, qianzhaoming. An improved lossless equalization charge circuit for VRLA battery [J]. power electronics technology. 2003.

6. Liu Hao, Xie Hua, jiangjiuchun, Research on SOC estimation scheme for $\mathrm{Li}$ - ion batteries for pure electric vehicles [J]. Electrical technology. 2010.

7. Yoon-Ho Kim. Design of Interface Circuits With Electrical Battery Models [J]. IEEE Transactions on Industrial Electronics. 2013. 